\title{
Anthocyanin-rich extract of jabuticaba epicarp as a natural colorant: Optimization of heat- and ultrasound-assisted extractions and application in
} a bakery product

\author{
Bianca R. Albuquerque ${ }^{\mathrm{a}, \mathrm{b}}$, José Pinela ${ }^{\mathrm{a}}$, Lillian Barros $^{\mathrm{a}, *}$, M. Beatriz P.P. Oliveira ${ }^{\mathrm{b}}$, \\ Isabel C.F.R. Ferreira ${ }^{\mathrm{a}, *}$ \\ ${ }^{a}$ Centro de Investigação de Montanha (CIMO), Instituto Politécnico de Bragança, Campus de Santa Apolónia, 5300-253 Bragança, Portugal \\ ${ }^{\mathrm{b}}$ REQUIMTE/LAQV, Faculdade de Farmácia, Universidade do Porto, Rua Jorge Viterbo Ferreira, 228, 4050-313 Porto, Portugal
}

\section{A R T I C L E I N F O}

\section{Keywords:}

Jabuticaba epicarp

Anthocyanins

Natural colorants

Extraction optimization

Colour stability

\begin{abstract}
A B S T R A C T
Heat- and ultrasound-assisted extractions of anthocyanins from jabuticaba epicarp were optimized and the colouring potential of the developed extract was tested on macarons. The independent variables time $(t)$, solvent concentration $(S)$, and temperature $(T)$ or power $(P)$ were combined in a five-level central composite design coupled with response surface methodology. The delphinidin-3-O-glucoside and cyanidin-3-O-glucoside levels monitored by HPLC-DAD-ESI/MS were used as response criteria. The developed models were successfully fitted to the experimental data and used to determine optimal extraction conditions. HAE was the most efficient method yielding $81 \pm 2 \mathrm{mg} / \mathrm{g}$ extract under optimal conditions $\left(t=21.8 \mathrm{~min}, T=47.1{ }^{\circ} \mathrm{C}\right.$ and $S=9.1 \%$ ethanol, $v / v$ ). Macarons were then produced using the optimized anthocyanin-rich colouring extract and their colour parameters and nutritional profile were monitored during shelf-life. The obtained results provided useful information for the development of anthocyanin-rich extracts from a bio-waste with potential use as natural food colorants.
\end{abstract}

\section{Introduction}

Colour is the main sensory aspect in foodstuff and an important requisite to consumer choice. The loss of natural colour in food during processing and storage and the search for more attractive aspect products are factors responsible for the use of colour additives by the food industry. For this finality, artificial colorants are preferred because they present higher stability, colouring power and are cheaper than natural colorants (Martins, Roriz, Morales, Barros, \& Ferreira, 2016).

In recent decades there has been a growing concern about the potential risks of artificial colours to human health, which has lead the modern food industry replace these kinds of additive by alternative natural colorants, which, in addition to colour power, can also provide bioactive proprieties to formulated products (Basu \& Kumar, 2015b, 2015a; Martins \& Ferreira, 2017; Masone \& Chanforan, 2015). For this reason, obtaining natural pigments for used as natural colorants has become an emerging research area. In addition, the valorisation of bioresidues has been of great interest for the production of value-added colorant compounds for use by various industries, such as nutraceutical and food (Martins \& Ferreira, 2017), being a sustainable approach that allows meeting current needs of the industry and the demands of society without causing a defect in food demand.

Jabuticaba (Myrciaria jaboticaba (Vell.) Berg.) is a native Brazilian berry that is not usually consumed and generates high amount of residue during the manufacture of jabuticaba pulp-based products. The fruit has a purple-dark thick epicarp with a high amount of anthocyanins (Albuquerque et al., 2020). Anthocyanins are flavonoids that showed attractive colours, ranging from red to purple, and are allowed for use as food colorants by EFSA with the E163 code (EFSA, 2013). In addition to colour, anthocyanins have also gained attention due to their potential health benefits, such as diabetes control and prevention of cardiovascular diseases and neurological disorders (Leong, Show, Lim, Ooi, \& Ling, 2018; Li, Wang, Luo, Zhao, \& Chen, 2017; You et al., 2018).

The recovery of anthocyanins from natural sources, such as fruits and flowers, is not always easy and feasible for application on an

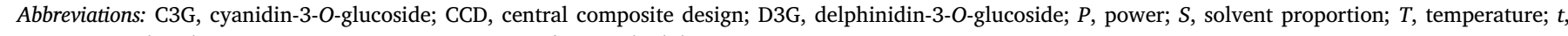
time; TAC, total anthocyanin content; RSM, response surface methodology

* Corresponding authors.

E-mail addresses: lillian@ipb.pt (L. Barros), iferreira@ipb.pt (I.C.F.R. Ferreira).
} 
Table 1

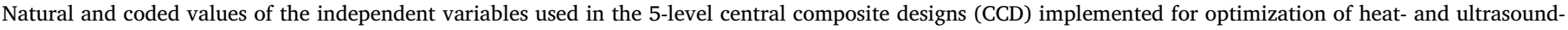
assisted extraction methods using the response surface methodology (RSM).

\begin{tabular}{|c|c|c|c|c|c|c|}
\hline \multirow[t]{3}{*}{ Coded values } & \multicolumn{6}{|c|}{ Natural values } \\
\hline & \multicolumn{3}{|c|}{ Heat-assisted extraction (HAE) } & \multicolumn{3}{|c|}{ Ultrasound-assisted extraction (UAE) } \\
\hline & $\begin{array}{l}\text { Time } \\
X_{A}(\min )\end{array}$ & $\begin{array}{l}\text { Temperature } \\
X_{B}\left({ }^{\circ} \mathrm{C}\right)\end{array}$ & $\begin{array}{l}\text { Solvent proportion } \\
X_{C}(\%, v / v)\end{array}$ & $\begin{array}{l}\text { Time } \\
X_{A}(\min )\end{array}$ & $\begin{array}{l}\text { Power } \\
X_{B}(\mathrm{~W})\end{array}$ & $\begin{array}{l}\text { Solvent proportion } \\
X_{C}(\%, v / v)\end{array}$ \\
\hline-1.68 & 5 & 20 & 0 & 5 & 100 & 0 \\
\hline-1 & 21.2 & 34.2 & 20.3 & 9.1 & 181.1 & 20.3 \\
\hline 0 & 55 & 45 & 50 & 15 & 300 & 50 \\
\hline 1 & 68.8 & 75.8 & 79.7 & 20.9 & 418.9 & 79.7 \\
\hline 1.68 & 85 & 90 & 100 & 25 & 500 & 100 \\
\hline
\end{tabular}

industrial scale, since the extraction of these compounds is a delicate process due to their poor stability. High temperature, $\mathrm{pH}$ change, and presence of light are some factors that can lead to their degradation. Among them, temperature and $\mathrm{pH}$ are among the most relevant factors during processing (Ngamwonglumlert, Devahastin, \& Chiewchan, 2017; Pinela et al., 2019). Nevertheless, applying heat to an extraction process is important to promote mass transfer phenomena, which increases process efficiency (Albuquerque et al., 2017). Therefore, the recovery of these compounds is very specific and requires a study to control the variables that can influence the process efficiency. A way around the extraction limitations of these compounds is by combining the variables or factors that provide the maximum yield of the tangent compound under viable experimental conditions. Also, the choice of an appropriate extraction method is crucial to the success of the process (Backes et al., 2018; Pinela et al., 2019). The response surface methodology (RSM) has been proposed to provide information regarding the optimal combination of extraction factors to obtain natural colorants from plant origin (Backes et al., 2018; López et al., 2018; Ordóñez-Santos, PinzónZarate, \& González-Salcedo, 2015; Pinela et al., 2019), and several methods have been described for anthocyanins recovery, such as maceration (Ćujić et al., 2016), heat-assisted extraction (HAE) (Backes et al., 2018; Khazaei, Jafari, Ghorbani, \& Kakhki, 2016; López et al., 2018), ultrasound-assisted-extraction (UAE) (Backes et al., 2018; Espada-Bellido et al., 2017; He et al., 2016; López et al., 2018; Pinela et al., 2019), microwave-assisted extraction (Backes et al., 2018; Zou et al., 2012), accelerant-solvent extraction (Cai et al., 2016), and supercritical fluid extraction (Maran, Priya, \& Manikandan, 2014). However, the specificities of each matrix have limited the extrapolation of condition conditions to the different anthocyanin sources. For example, UAE was more effective than HAE in the extraction of anthocyanins from Hibiscus sabdariffa calyces and Ficus carica L. peels (Backes et al., 2018; Pinela et al., 2019), but for Arbutus unedo L. fruit, HAE was the best method when compared to UAE (López et al., 2018).

This study was carried out to develop an anthocyanin-rich extract from jabuticaba epicarp, namely: i) by optimizing the extraction by the HAE and UAE methods using RSM; and ii) by validating the colouring capacity of the extract obtained under optimized conditions by incorporating it into a food matrix, namely macarons. A schematic representation of the different steps carried out in this work is illustrated in Fig. S1.

\section{Material and methods}

\subsection{Plant material}

Jabuticaba (Myrciaria jaboticaba (Vell.) O. Berg.) fruits were acquired from CEAGESP (Companhia de Entrepostos e Armazéns Gerais de São Paulo), Brazil, through the Unidos distributor. The fruits were washed and the epicarp was manually separated from the pulp. The epicarps were then frozen at $-20{ }^{\circ} \mathrm{C}$ and lyophilized at $10 \mu \mathrm{Hg}$ and $-55{ }^{\circ} \mathrm{C}$ (Enterprise I, Terroni, São Carlos, SP, Brazil) in the Instituto
Mauá de Tecnologia in São Caetano do Sul, Brazil, and sent under the best condition to the Centro de Investigação de Montanha in Bragança, Portugal, where they were reduced to a fine and homogeneous powder $(\sim 20$ mesh $)$ and stored at $-20{ }^{\circ} \mathrm{C}$ until analysis.

\subsection{Standards and reagents}

HPLC-grade formic acid and acetonitrile were supplied from Fisher Scientific (Lisbon, Portugal). The standards cyanidin-3-O-glucoside, fructose, glucose, sucrose, and melezitose were purchased from SigmaAldrich (St. Louis, MO, USA). All other chemicals and solvents were of analytical grade and purchased from common suppliers. Water was treated in a Milli-Q water purification system (TGI Pure Water Systems, Greenville, SC, USA).

\subsection{Experimental design for extraction optimization}

A five-level central composite design (CCD) coupled with RSM was implemented to optimize the extraction of anthocyanins from jabuticaba epicarps. The coded and natural values of the independent variables $X_{A}$ (time: $t, \min$ ), $X_{B}$ (temperature: $T$, ${ }^{\circ} \mathrm{C}$, or power: $P, \mathrm{~W}$ ), and $X_{C}$ (solvent proportion: $S, \%$ ethanol, $v / v$ ) are presented in Table 1 . The 20 experimental points of the CCD design shown in Table 2 were generated using Design-Expert software, Version 11 (Stat-Ease, Inc., Minneapolis, USA) by entering factor ranges in terms of alphas $(\alpha=1.68)$. This rotatable design included 6 replicated centre points and a group of axial points chosen to allow rotatability, which ensures that the variance of the model prediction is constant at all points equidistant from the centre point of the design. The experimental runs were randomized to minimize the effects of unexpected variability in the observed responses.

\subsection{Extraction methods}

\subsubsection{Heat-assisted extraction}

The heat-assisted extraction (HAE) was performed in a thermostated water bath using sealed vessels to avoid solvent evaporation. Ethanol was used in the extractions due its low toxicity and efficiency in the recovery of phenolic compounds, including anthocyanins (Boulekbache-Makhlouf, Medouni, Medouni-Adrar, Arkoub, \& Madani, 2013). Powdered jabuticaba epicarps ( $1 \mathrm{~g}$ ) were mixed with $20 \mathrm{~mL}$ of solvent (ethanol: water mixtures acidified with citric acid at $\mathrm{pH} 3$ ) and processed under continuous magnetic stirring at $500 \mathrm{rpm}$, according to the experimental design matrix in Table 2, where different levels of $t$ (5-85 $\mathrm{min}), T\left(20-90{ }^{\circ} \mathrm{C}\right)$ and $S(0-100 \%)$ are combined. The solid/ liquid ratio $(S / L)$ was kept at $50 \mathrm{~g} / \mathrm{L}$. After processing, the mixture was centrifuged at $480 \mathrm{~g}$ for $10 \mathrm{~min}$ and the supernatant was carefully collected and stored at $-80{ }^{\circ} \mathrm{C}$ until analysis.

\subsubsection{Ultrasound-assisted extraction}

The ultrasound-assisted extraction (UAE) was performed using an 
Table 2

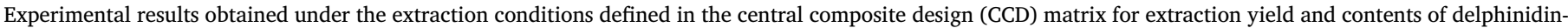

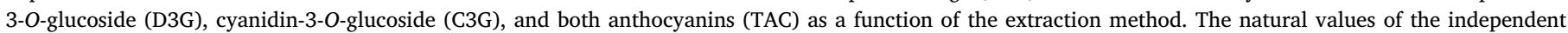
variables $X_{A}$ (time), $X_{B}$ (temperature or power) and $X_{C}$ (solvent proportion) are presented in Table 1.

\begin{tabular}{|c|c|c|c|c|c|c|c|c|c|c|c|}
\hline \multirow[t]{3}{*}{ Run } & \multirow{2}{*}{\multicolumn{3}{|c|}{$\frac{\text { CCD design }}{\text { Coded values }}$}} & \multicolumn{4}{|c|}{ Heat-assisted extraction (HAE) } & \multicolumn{4}{|c|}{ Ultrasound-assisted extraction (UAE) } \\
\hline & & & & \multirow{2}{*}{$\begin{array}{l}\text { Yield } \\
\%\end{array}$} & \multirow{2}{*}{$\begin{array}{l}\text { D3G } \\
\mathrm{mg} / \mathrm{g} \mathrm{E}\end{array}$} & \multirow{2}{*}{$\begin{array}{l}\text { C3G } \\
\mathrm{mg} / \mathrm{g} \mathrm{E}\end{array}$} & \multirow{2}{*}{$\begin{array}{l}\text { TAC } \\
\mathrm{mg} / \mathrm{g} \mathrm{E}\end{array}$} & \multirow{2}{*}{$\begin{array}{l}\text { Yield } \\
\%\end{array}$} & \multirow{2}{*}{$\begin{array}{l}\text { D3G } \\
\mathrm{mg} / \mathrm{g} \mathrm{E}\end{array}$} & \multirow{2}{*}{$\begin{array}{l}\mathrm{C} 3 \mathrm{G} \\
\mathrm{mg} / \mathrm{g} \mathrm{E}\end{array}$} & \multirow{2}{*}{$\begin{array}{l}\text { TAC } \\
\mathrm{mg} / \mathrm{g} \mathrm{E}\end{array}$} \\
\hline & $X_{A}$ & $X_{B}$ & $X_{C}$ & & & & & & & & \\
\hline 1 & -1 & -1 & -1 & 52.4 & 6.11 & 54.61 & 60.73 & 26.7 & 2.24 & 24.10 & 26.34 \\
\hline 2 & -1 & -1 & 1 & 51.4 & 3.72 & 13.92 & 17.64 & 32.5 & 2.61 & 9.33 & 11.94 \\
\hline 3 & -1 & 1 & -1 & 54.5 & 12.25 & 55.82 & 68.08 & 48.0 & 3.05 & 30.96 & 34.01 \\
\hline 4 & -1 & 1 & 1 & 48.4 & 3.24 & 15.69 & 18.93 & 55.4 & 2.67 & 14.90 & 17.57 \\
\hline 5 & 1 & -1 & -1 & 57.2 & 4.25 & 41.67 & 45.92 & 50.2 & 1.96 & 27.61 & 29.57 \\
\hline 6 & 1 & -1 & 1 & 50.9 & 3.64 & 15.55 & 19.19 & 44.7 & 2.52 & 11.04 & 13.56 \\
\hline 7 & 1 & 1 & -1 & 54.7 & 10.54 & 47.71 & 58.25 & 54.4 & 2.66 & 19.75 & 22.41 \\
\hline 8 & 1 & 1 & 1 & 53.0 & 3.24 & 15.69 & 18.93 & 59.3 & 2.89 & 15.10 & 17.99 \\
\hline 9 & -1.68 & 0 & 0 & 54.8 & 3.68 & 21.62 & 25.30 & 58.7 & 3.23 & 17.62 & 20.85 \\
\hline 10 & 1.68 & 0 & 0 & 58.1 & 3.36 & 20.19 & 23.55 & 54.0 & 3.69 & 23.52 & 27.21 \\
\hline 11 & 0 & -1.68 & 0 & 57.9 & 2.62 & 17.51 & 20.13 & 26.1 & 3.78 & 15.98 & 19.76 \\
\hline 12 & 0 & 1.68 & 0 & 56.9 & 3.78 & 21.04 & 24.82 & 57.4 & 4.92 & 23.41 & 28.33 \\
\hline 13 & 0 & 0 & -1.68 & 44.5 & 10.47 & 49.23 & 59.70 & 48.8 & 1.90 & 17.66 & 19.55 \\
\hline 14 & 0 & 0 & 1.68 & 32.8 & 3.78 & 21.04 & 24.82 & 24.9 & 2.51 & 7.30 & 9.81 \\
\hline 15 & 0 & 0 & 0 & 54.7 & 3.41 & 20.24 & 23.65 & 56.8 & 4.03 & 23.04 & 27.07 \\
\hline 16 & 0 & 0 & 0 & 57.0 & 3.32 & 20.83 & 24.15 & 52.8 & 4.34 & 25.90 & 30.25 \\
\hline 17 & 0 & 0 & 0 & 57.2 & 3.33 & 20.47 & 23.80 & 53.9 & 4.15 & 24.36 & 28.51 \\
\hline 18 & 0 & 0 & 0 & 55.1 & 3.80 & 22.08 & 25.82 & 56.0 & 4.05 & 24.17 & 28.23 \\
\hline 19 & 0 & 0 & 0 & 56.3 & 3.49 & 20.70 & 24.19 & 56.3 & 4.34 & 24.86 & 29.20 \\
\hline 20 & 0 & 0 & 0 & 54.8 & 3.32 & 19.99 & 23.31 & 54.9 & 3.47 & 22.05 & 25.52 \\
\hline
\end{tabular}

E: dried extract.

ultrasonic system (Ultrasonic homogenizer, model CY-500, Optic Ivymen Systen, Barcelona, Spain) equipped with a titanium probe and a connector for the sample temperature control. Powdered jabuticaba epicarps $(2.5 \mathrm{~g})$ were placed in a beaker with $50 \mathrm{~mL}$ of solvent and processed according to the experimental design matrix in Table 2, where different levels of $t$ (5-25 $\mathrm{min}), P(100-500 \mathrm{~W}$; at a frequency of $20 \mathrm{kHz})$ and $S(0-100 \%)$ are combined. The $S / L$ was kept constant (50 g/L), as well as $T\left(30-35{ }^{\circ} \mathrm{C}\right.$; a cold water bath was used to avoid heating the samples). The mixtures were then centrifuged and the supernatant collected as described for HAE.

\subsection{Response variable analysis for extraction process optimization}

\subsubsection{Evaluation of the extraction yield}

The extract weight resulting from each extraction was determined gravimetrically in crucibles by evaporation of $5 \mathrm{~mL}$ of supernatant (extract solution) at $105{ }^{\circ} \mathrm{C}$ for $24 \mathrm{~h}$. The results were expressed as percentage of crude extract per plant material $(\%, w / w)$.

\subsubsection{Chromatographic analysis of anthocyanin contents}

A portion $(1.5 \mathrm{~mL})$ of each extract solution was filtered through $0.22 \mu \mathrm{m}$ disposable syringe filters and analysed in a Dionex Ultimate 3000 HPLC system (Thermo Scientific, San Jose, CA, USA), operating under the conditions described in detail by Gonçalves et al. (2017). Compound detection was carried out with a diode array detector (DAD) at a wavelength of $520 \mathrm{~nm}$. Chromatographic data were acquired and processed using Xcalibur software (Thermo Finnigan, San Jose, CA, USA). Anthocyanins were characterized according to their UV-Vis and mass spectra, and quantification was performed using a calibration curve constructed with cyanidin-3-O-glucoside (y $=134578 \mathrm{x}-$ 3000000; $R^{2}=0.999$ ). The total anthocyanin content was determined by sum of the quantified anthocyanins. The results were expressed as mg per $g$ of dry extract (E).

\subsection{Extraction process modelling and optimization}

\subsubsection{Response criteria and mathematical modelling}

The dependent variables $Y_{1}$ (extraction yield), $Y_{2}$ (delphinidin-3-Oglucoside content, D3G), $Y_{3}$ (cyanidin-3-O-glucoside content, C3G), and $Y_{4}$ (total anthocyanin content, TAC) were used to optimize the recovery of anthocyanins from jabuticaba epicarp. The response surface models were fitted by means of last-squares calculation using the following second-order quadratic polynomial equation:

$Y=b_{0}+\sum_{i=1}^{n} b_{i} X_{i}+\sum_{\substack{i=! \\ J>1}}^{n-1} \sum_{j=2}^{n} b_{i j} X X_{j}+\sum_{i=1}^{n} b_{i i} X_{i}^{2}$

where $Y$ represents the dependent (response) variable to be modelled; $b_{o}$ is the constant coefficient and $b_{i}, b_{i i}$ and $b_{i j}$ indicate the regression coefficient for the linear, quadratic and interaction effects, respectively; $X_{i}$ and $X_{j}$ represent the independent variables; and $n$ shows the number of variables involved (therefore, $n=3$ ).

\subsubsection{Fitting procedures and statistical analysis}

Fitting procedures, coefficient estimates and statistical calculations were performed using Design-Expert software, Version 11. The analyses of variance (ANOVA) was used to determine the regression coefficients and to assess the significance of the data. The coefficient of determination $\left(R^{2}\right)$ and the adjusted coefficient of determination $\left(R_{a d j}^{2}\right)$, interpreted as the proportion of variability of the dependent variable explained by the model (Albuquerque et al., 2018), were used to estimate the fitness of the polynomial equation to the response. Only the statistically significant terms ( $p$-value $<0.05$ ) were used to fit the mathematical models. The significance of all the terms of the polynomial equations was analysed statistically by computing the F-value at $p<0.05$. The statistic lack of fit was used to evaluate the adequacy of the models. This test shows whether the model adequately describes the functional relationship between the independent variables and the obtained response. Thus, the lack of fit should be non-significant $(p>0.05)$. The software was also used to generate the response surface graphs. 
2.7. Validation of the colorant potential of the anthocyanin-rich extract in a bakery product

\subsubsection{Formulation of macarons}

A traditional recipe of French macarons containing 28\% almond flour, $28 \%$ sugar powder, $23 \%$ egg whites, and $23 \%$ sugar was followed. Due the amount of egg whites $(\mathrm{pH} \sim 7)$ added to the macaron formulation, lemon juice $(\mathrm{pH} \sim 2.2)$ was added $(1: 4, v / w)$ to decrease the $\mathrm{pH}$ and thereby increase the anthocyanin stability, preventing a change colour. The dough was then coloured with the anthocyanin-rich extract (AE) obtained under the optimized extraction conditions and with the commercial colorant E163 (used as control). The macarons were baked in a conventional oven for $13 \mathrm{~min}$ at $130{ }^{\circ} \mathrm{C}$. The two batches of macarons were then divided into three groups: one was immediately analysed (T1) and the other two were analysed after three (T2) and six (T3) days of storage at $\pm 5{ }^{\circ} \mathrm{C}$, protected from sunlight and in plastic bags. Then, after measuring the colour, the macarons were lyophilized, crushed, and analysed in triplicate for their nutritional value.

\subsubsection{Colour analysis}

The colour of macarons was measured with a colorimeter (model CR-400, Konica Minolta Sensing Inc., Tokyo, Japan) previously calibrated against a standard white tile (López et al., 2019). Using illuminant $\mathrm{C}$ and an $8 \mathrm{~mm}$ diaphragm aperture, the CIE $L^{*}$ (lightness), $a^{*}$ (greenness-redness), and $b^{*}$ (blueness-yellowness) colour space values were recorded using Spectra Magic Nx software (version CM-S100W 2.03.0006).

\subsubsection{Nutritional composition analysis}

The moisture content of macarons was determined using a moisture analyser (model PBM 163, Adam Equipment Inc., Oxford, EUA). The protein, fat, and ash contents were determined following the AOAC procedures (AOAC International, 2016). Briefly, the crude protein content $(\mathrm{N} \times 5.18)$ was estimated by the macro-Kjeldahl method (AOAC 978.04), using an automatic distillation and titration unit (ProNitro-A, JP Selecta, Barcelona); the crude fat content was determined by Soxhlet extraction with petroleum ether (AOAC 920.85); and the ash content was determined by incineration in a muffle furnace at $600 \pm 15{ }^{\circ} \mathrm{C}$ for $5 \mathrm{~h}$ (AOAC 923.03). The total carbohydrate content was estimated by difference. The results were expressed as $\mathrm{g}$ per $100 \mathrm{~g}$ of dry weight $(\mathrm{dw})$.

The energy value was calculated according to Regulation (EU) No 1169/2011 of the European Parliament and of the Council (2011) as follows: $4 \times$ ( $\mathrm{g}$ protein $+\mathrm{g}$ carbohydrates $)+9 \times(\mathrm{g}$ fat $)$, and given as kcal per $100 \mathrm{~g}$ of dry weight $(\mathrm{dw})$.

Free sugars were analysed in a high performance liquid chromatography system (HPLC, Knauer, Smartline system 1000, Berlin, Germany) coupled to a refractive index (RI) detector (Knauer Smartline 2300), following analytical procedures previously described by Barros et al. (2013). Chromatographic data were acquired and analysed using Clarity 2.4 software (DataApex). Quantification was performed by comparing the area of the sample peaks with calibration curves obtained from commercial standards, using the internal standard method (IS, melezitose). The results were expressed as $\mathrm{g}$ per $100 \mathrm{~g}$ of dry weight (dw).

\subsubsection{Statistical analysis}

Colour and nutritional analyses were performed in triplicate and the results were expressed as mean \pm standard deviation. The statistical analysis was performed at a 5\% significance level using SPSS Statistics software (IBM SPSS Statistics for Windows, Version 23.0, IBM Corp., Armonk, NY, USA). A two-tailed paired Student's $t$-test was applied for assessing statistical differences $(p<0.05)$ between AE and control samples, while a one-way ANOVA was applied for assessing the effect of storage time on the evaluated parameters. The fulfilment of the ANOVA requirements, specifically the normal distribution of the residuals and the homogeneity of variance, was tested by means of the Shapiro Wilk's and Levene's tests, respectively. Data were compared using Tukey's honestly significant difference (HSD) test.

\section{Results and discussion}

\subsection{Optimization of the extraction of anthocyanins}

Although the extraction of anthocyanins from jabuticaba epicarp has been described in previous studies (Paludo et al., 2019; Rodrigues, Fernandes, de Brito, Sousa, \& Narain, 2015; Santos \& Meireles, 2011; Santos, Veggi, \& Meireles, 2012), this is the first work to optimize the HAE process. In addition, an easy-to-apply, low-investment, conventional method (HAE) is compared with a non-conventional method (UAE) whose acoustic cavitation effect can improve mass transfer and thus reduce processing time and increase the extraction yield (Pinela et al., 2019). It is also describes the individual behaviour of two anthocyanin previously identified by Albuquerque et al. (2019) in jabuticaba epicarp against the studied extraction variables (t, $T, P$, and $S$ ).

\subsubsection{Experimental data obtained with the CCD design}

The experimental results obtained with the 20 runs of the 5-level CCD design matrix implemented to optimize the HAE and UAE processes used to extract anthocyanins from jabuticaba epicarp are shown in Table 2. The extraction yield ranged from 32.8 to $58.1 \%$ with HAE and from 24.9 to $59.3 \%$ with UAE. In both cases, the lowest extraction yields were obtained with run 14, which combined medium $t$ and $T$ or $P$ conditions (55 min and $45{ }^{\circ} \mathrm{C}$ for HAE and $15 \mathrm{~min}$ and $300 \mathrm{~W}$ for UAE; $\alpha=0$ ) with a high solvent concentration (100\% ethanol, $v / v$; $\alpha=1.68$ ). Regarding anthocyanins, cyanidin-3-O-glucoside (C3G) was detected in greater quantity than delphinidin-3-O-glucoside (D3G) in all extracts, with concentrations ranging from 13.92 to $55.82 \mathrm{mg} / \mathrm{g} E$ and 7.30 to $30.96 \mathrm{mg} / \mathrm{g}$ E with the HAE and UAE processes, respectively, while the D3G levels ranged from 2.62 to $12.25 \mathrm{mg} / \mathrm{g}$ E with HAE and from 1.90 to $4.34 \mathrm{mg} / \mathrm{g}$ E with UAE. For both methods, the highest levels of total anthocyanins (TAC; $68.08 \mathrm{mg} / \mathrm{g}$ for HAE and $34.01 \mathrm{mg} / \mathrm{g}$ for UAE) were achieved with run 3 , which employed a short-moderate $t$ (21.2 min for HAE and 9.1 min for UAE; $\alpha=-1$ ), a medium-high $T$ or $P$ $\left(75,8{ }^{\circ} \mathrm{C}\right.$ or $\left.418.9 \mathrm{~W} ; \alpha=1\right)$ and a low-moderate $S$ concentration (20.3\% ethanol, $v / v ; \alpha=-1$ ). As verified for yield responses, higher ethanol concentrations also had a negative effect on anthocyanin extraction by the UAE method, as only $9.81 \mathrm{mg}$ TAC/g E were obtained with run 14 (Table 2). For HAE, the lowest TAC value $(17.81 \mathrm{mg} / \mathrm{g} \mathrm{E}$ ) was reached with run $2\left(21.2 \mathrm{~min}, 34.2{ }^{\circ} \mathrm{C}\right.$ and $79.7 \%$ ethanol, $\left.v / v\right)$, while run 3 (which differed only in temperature, $75.8{ }^{\circ} \mathrm{C}$ ) gave the highest content $(68.08 \mathrm{mg} / \mathrm{g}$ E). In general, the HAE method resulted in higher anthocyanin extraction rates than UAE.

\subsubsection{Analysis of the theoretical response surface models}

RMS is a mathematical and statistical analysis tool suitable for modelling and analysing processes involving one or more response variables, which allows to minimize the number of laboratorial experiments and maximized responses (Leichtweis et al., 2019). When trying to develop theoretical models to predict and comprehend the effects of independent variables on certain response variables, it is necessary to evaluate their precision by fitting these models to experimental values. In this study, the response values of Table 2 were fitted to the second-order polynomial model of Eq. (1) to develop the mathematical models (Eqs. (2-5) for each response criteria. However, not all parameters of Eq. (1) were used in the development of the models since some coefficients were non-significant (Table 3); the significant ones were assessed at a $95 \%$ confidence level $(\alpha=0.05)$.

For the HAE process:

$Y_{(\text {Yield })}=56.25-2.55 S-5.29 S^{2}$ 
Table 3

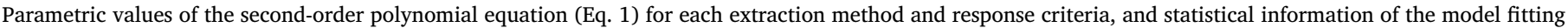
procedure. Parametric superscripted 1,2 and 3 stand for the variables time $\left(X_{A}\right)$, temperature or power $\left(X_{B}\right)$, and solvent proportion $\left(X_{C}\right)$, respectively.

\begin{tabular}{|c|c|c|c|c|c|c|c|c|c|}
\hline \multirow[b]{2}{*}{ Effect } & & \multicolumn{4}{|c|}{ Heat-assisted extraction (HAE) } & \multicolumn{4}{|c|}{ Ultrasound-assisted extraction (UAE) } \\
\hline & & Yield & D3G & C3G & TAC & Yield & D3G & C3G & TAC \\
\hline Intercept & $b_{o}$ & $56.25 \pm 0.71$ & $3.75 \pm 0.68$ & $20.89 \pm 0.92$ & $24.02 \pm 1.08$ & $54.50 \pm 2.32$ & $4.07 \pm 0.35$ & $22.57 \pm 2.00$ & $26.56 \pm 2.03$ \\
\hline \multirow[t]{3}{*}{ Linear effect } & $b_{1}$ & ns & ns & $-0.54 \pm 0.85$ & $-0.87 \pm 0.99$ & ns & $0.04 \pm 0.27$ & ns & ns \\
\hline & $b_{2}$ & ns & $0.96 \pm 0.64$ & $-0.41 \pm 0.85$ & $0.44 \pm 0.99$ & $8.64 \pm 1.38$ & $0.31 \pm 0.27$ & $1.55 \pm 1.83$ & $1.69 \pm 1.86$ \\
\hline & $b_{3}$ & $-2.55 \pm 0.67$ & $-2.32 \pm 0.64$ & $-9.69 \pm 1.21$ & $-1.63 \pm 1.68$ & $-2.85 \pm 1.48$ & $0.13 \pm 0.27$ & $-5.96 \pm 2.23$ & $-5.86 \pm 2.27$ \\
\hline \multirow[t]{3}{*}{ Quadratic effect } & $b_{11}$ & $\mathrm{~ns}$ & $\mathrm{~ns}$ & ns & $\mathrm{ns}$ & $\mathrm{ns}$ & $-0.35 \pm 0.26$ & $\mathrm{~ns}$ & ns \\
\hline & $b_{22}$ & $\mathrm{~ns}$ & ns & ns & ns & $-3.92 \pm 1.70$ & ns & ns & ns \\
\hline & $b_{33}$ & $-5.29 \pm 0.65$ & $1.42 \pm 0.62$ & $9.54 \pm 1.03$ & $9.82 \pm 1.47$ & $-2.53 \pm 1.77$ & $0.82 \pm 0.24$ & $-4.45 \pm 2.32$ & $-5.58 \pm 2.37$ \\
\hline \multirow[t]{3}{*}{ Interactive effect } & $b_{12}$ & $\mathrm{~ns}$ & ns & $1.52 \pm 1.43$ & $4.58 \pm 2.57$ & ns & ns & $\mathrm{ns}$ & ns \\
\hline & $b_{13}$ & ns & ns & $3.98 \pm 1.43$ & $7.74 \pm 2.52$ & ns & ns & ns & ns \\
\hline & $b_{23}$ & ns & $-1.64 \pm 0.84$ & $-2.04 \pm 1.43$ & $-7.15 \pm 2.53$ & $2.53 \pm 0.98$ & $\mathrm{~ns}$ & ns & ns \\
\hline \multirow[t]{4}{*}{ Statistical analysis } & SM & $<0.0001$ & $<0.0001$ & $<0.0001$ & $<0.0001$ & $<0.0001$ & 0.0002 & 0.0002 & $<0.0001$ \\
\hline & $\mathrm{LF}$ & 0.1454 & 0.0884 & 0.1693 & 0.1971 & 0.0769 & 0.1368 & 0.0531 & 0.0620 \\
\hline & $\mathrm{R}^{2}$ & 0.8269 & 0.8807 & 0.9882 & 0.9909 & 0.9521 & 0.8075 & 0.7290 & 0.7484 \\
\hline & $\mathrm{R}_{\mathrm{adj}}^{2}$ & 0.8065 & 0.8488 & 0.9826 & 0.9867 & 0.9388 & 0.7388 & 0.6748 & 0.6981 \\
\hline
\end{tabular}

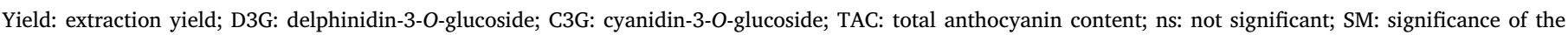
model; LF: lack of fit; $\mathrm{R}^{2}$ : coefficient of determination; $\mathrm{R}_{\text {ajd }}^{2}$ : adjusted coefficient of determination.

$Y_{(D 3 G)}=3.75+0.96 T-2.32 S+1.42 S^{2}-1.64 T S$

$Y_{(C 3 G)}$

$$
=20.89-0.54 t-0.41 T-9.69 S+9.54 S^{2}+1.52 t T+3.98 t S-2.04 T S
$$

$$
\begin{aligned}
& Y_{(T A C)} \\
& \quad=24.02-0.87 t+0.44 T-1.63 S+9.82 S^{2}+4.58 t T+7.74 t S-7.15 T S
\end{aligned}
$$

For the UAE process:

$$
\begin{aligned}
& Y_{(\text {Yield })}=54.50+8.64 T-2.85 S-3.92 T^{2}-2.53 S^{2}+2.53 T S \\
& Y_{(D 3 G)}=4.07+0.04 t+0.31 T+0.13 S-0.35 t^{2}+0.82 S^{2} \\
& Y_{(C 3 G)}=22.57+1.55 T-5.96 S-4.45 S^{2} \\
& Y_{(T A C)}=26.56+1.69 T-5.86 S-5.58 S^{2}
\end{aligned}
$$

The presented mathematical models reflect the complexity of extraction trends. The coefficient estimate represents the expected change in response per unit change in factor value when all remaining factors are held constant. The intercept in an orthogonal design is the overall average response of all the runs of the RSM design matrix (Table 2).

The parametric values of the second-order polynomial equation used to construct the mathematical models presented above and the statistical information of the model fitting procedure are presented in Table 3. All models presented a non-significant lack of fit, indicating that the equations adequately describe the effects of the variables on the evaluated responses with good predictability (Iberahim, Sethupathi, Goh, Bashir, \& Ahmad, 2019). The obtained coefficients $R^{2}$ and $R_{\text {adj }}^{2}$ were $\geq 0.83$ and 0.81 for HAE and $\geq 0.73$ and 0.67 for UAE (Table 3 ), which indicates that the variability of each response can be explained by the independent variables involved in the process. Additionally, these statistical data also indicate that the experimental values of HAE are closer to the ones predicted by the models, as can be seen in Part B of Figs. 1 and 2. The models proved to be statistically adequate and, therefore, were used to navigate the design space in the subsequent optimization steps. Although the model coefficients are empirical and do not reflect physical or chemical significance, they are useful to predict the outcome of untested experimental conditions (Pinela et al., 2018). In addition, the parametric value sign determines part of the response. Thus, for variables with a positive coefficient value, the response is higher at the high level, while for a negative coefficient value, the response is lower at the high level. The higher the parametric value, the more significant is the weight of the variable (Pinela et al., 2019).

Certain features regarding the overall effects of the independent variables can be inferred from the complexity of the parametric values (Table 3), i.e., the variables can be ordered in a decreasing form as a function of its significance in the extraction processes as follows: $S>T$ or $P>t$. It is also possible to observe that some of the evaluated responses were significantly affected by linear and quadratic effects, mainly caused to the variable $S$ (for HEA, $t$ and $T$ had no significant quadratic effects). The parametric values also show the existence of interactions between the three variables involved in the anthocyanin extraction by HAE, while only the yield was affected by $T \times S$ in the UAE process. These results justify the use of RSM as an optimization tool, since one-variable-at-a-time approaches do not evaluate the existence of interactions, which makes the determination of optimum values difficult.

\subsubsection{Effect of the independent variables on the target responses}

To visually describe the extraction trends, the results were presented as 3D response surface graphs, which illustrate the effect of the three studied independent variables on the extraction yield and anthocyanins content for both HAE (Fig. 1) and UAE (Fig. 2) methods. The net surfaces of each graph were predicted with the second-order polynomial Eq. (1), whose model equations are presented above. For representation of binary actions, the excluded variable in each graph was fixed constant (cte) as indicated. Additionally, the goodness of fit of the models was illustrated by the ability to simulate response changes between the observed and predicted data (Figs. 1 and 2, Part B).

For the extraction yield, it is possible to observe that, in the HAE process (Fig. 1), the response was significantly affected only by the ethanol concentration (Table 3), whose effect is perfectly illustrated by the curvature of the graphs surface where this variable is represented. The increase of this variable up to about $50 \%$ increased extraction yield, but thereafter it decreased through a quadratic effect. For UAE (Fig. 2), the ultrasound power was the most relevant variable, followed by the ethanol concentration (Table 3 ). The higher the ultrasound power, the higher the extraction yield. A positive interaction between the two variables $(P \times S)$ was also verified (Table 3 ), which once again justifies the use of RSM for optimization. In both processes, the variable time had no significant effect on this response.

Regarding anthocyanins, the response surfaces obtained for HAE were more complex than those of UAE (Figs. 1 and 2), as predicted by the developed theoretical models. In general, the HAE extraction of both anthocyanins was favoured by higher temperatures and lower ethanol concentrations. The extraction time affected negatively the 


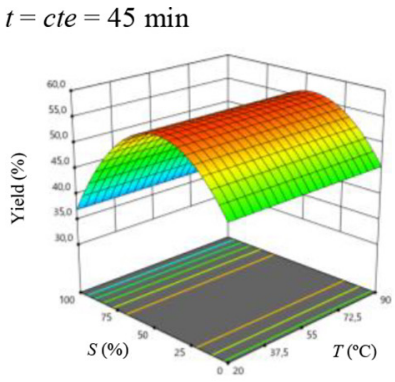

$T=c t e=50^{\circ} \mathrm{C}$

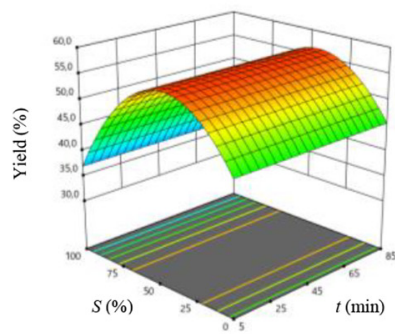

$S=c t e=42.8 \%$

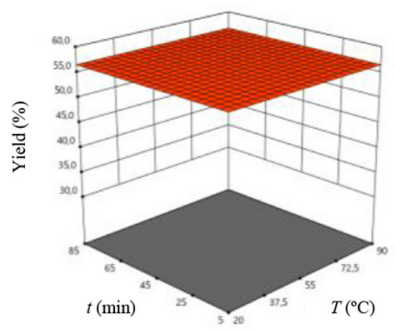

$t=c t e=25 \mathrm{~min}$

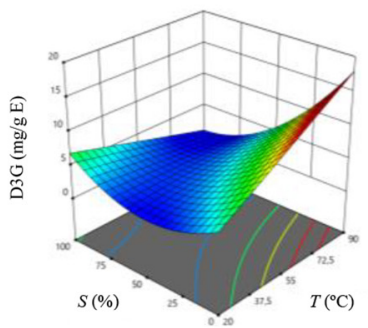

$T=c t e=75^{\circ} \mathrm{C}$

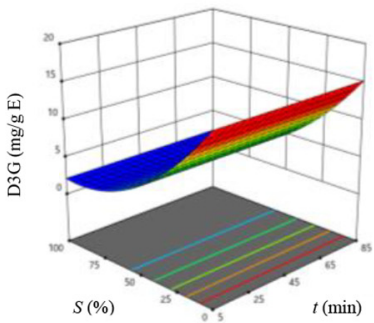

$S=c t e=5 \%$

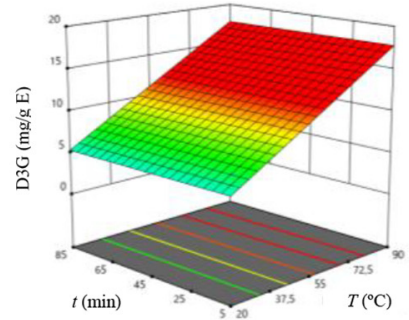

$t=c t e=25 \mathrm{~min}$

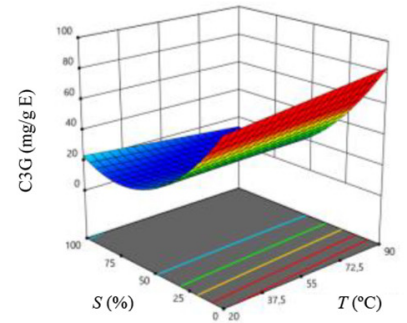

$T=c t e=50^{\circ} \mathrm{C}$

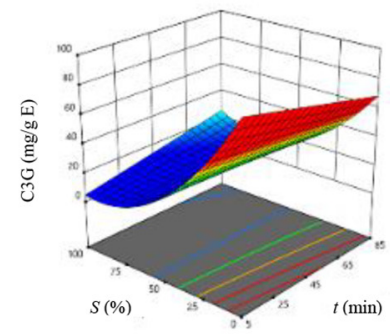

$S=c t e=5 \%$

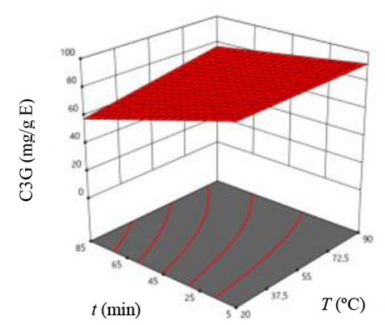

$t=c t e=25 \mathrm{~min}$

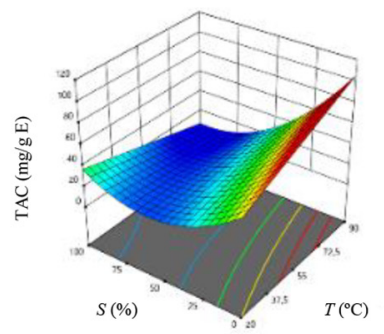

$T=c t e=60^{\circ} \mathrm{C}$

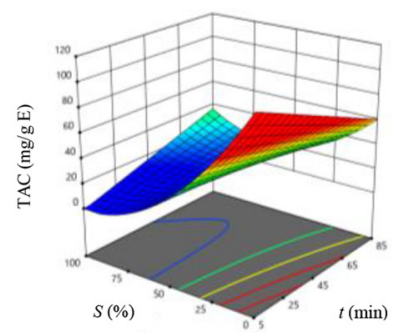

$S=c t e=5 \%$

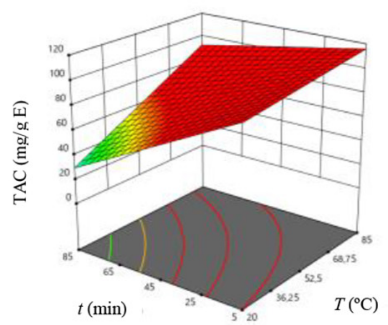

\section{Part B: Statistical distribution}
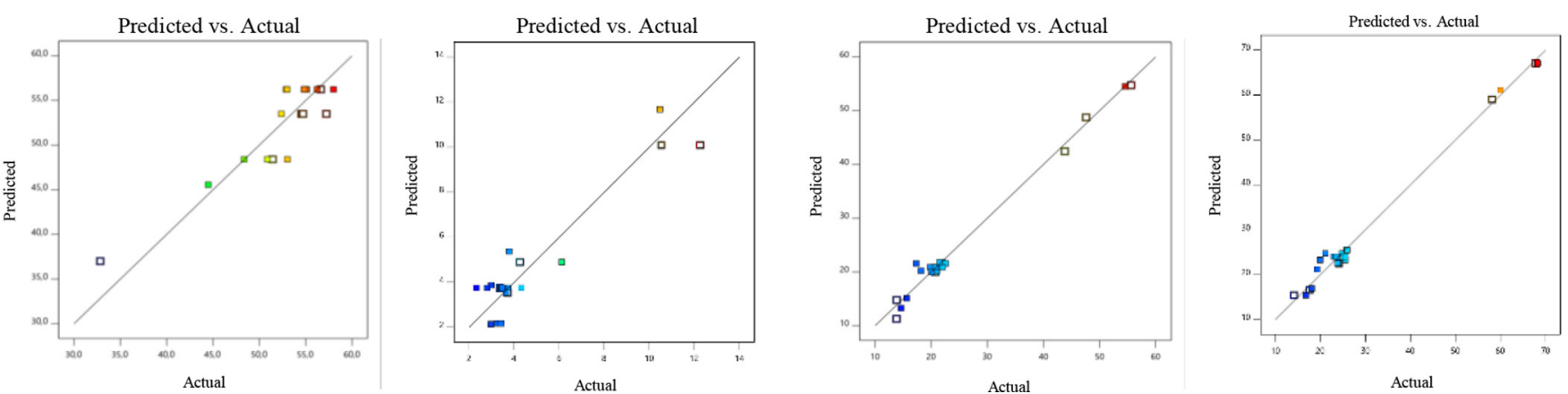

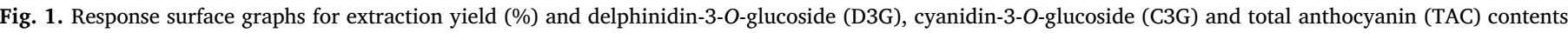

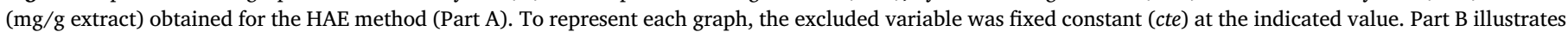
the goodness of fit through the ability to simulate response changes between actual and predicted values.

recovery of C3G (the anthocyanin found in higher amount) and, consequently, the total anthocyanin content (TAC); thus, the longer the extraction time, the lower the anthocyanin recovery. This is probably due to the breakdown of the structure of these sensitive compounds when subjected to longer processing times (López et al., 2019). Also noteworthy are the quadratic effects of the solvent and the positive interactions between $t \times S$ and $t \times T$, and the negative ones between $T \times S$ (Table 3). Meanwhile, in the UAE extraction, the highest amounts of anthocyanins were obtained when the jabuticaba epicarp samples were sonicated with a high power in a medium-low ethanol:water mixture. This last variable was the one that most affected the extraction, with quadratic effects marked on the surface graphs (Fig. 2). In the particular case of C3G, its extraction was also affected by the variable time; increasing the processing time up to about 15 min was beneficial for extraction but decreased thereafter.

\subsubsection{Optimal extraction conditions and comparison of the HAE and UAE methods}

From the response surface graphs shown in Figs. 1 and 2 it is possible to infer that an optimal extraction value can be found as a single point in almost all combinations. Therefore, the extraction conditions that lead to an absolute maximum were computed (Table S1). The conditions that maximized the HAE extraction were as follows:

- For extraction yield, the conditions were: $t=9.31 \mathrm{~min}$, $T=34.47{ }^{\circ} \mathrm{C}$, and $S=42.79 \%$ ethanol $(v / v)$, and originated $56.6 \pm 0.7 \%(w / w)$ of extract.

- For D3G, the conditions were: $t=5.68 \mathrm{~min}, T=68.21{ }^{\circ} \mathrm{C}$, and $S=0.09 \%$ ethanol $(v / v)$, and yielded $14 \pm 1 \mathrm{mg} / \mathrm{g}$ extract.

- For C3G, the conditions were: $t=7.89 \mathrm{~min}, T=25.18{ }^{\circ} \mathrm{C}$, and $S=11.78 \%$ ethanol $(v / v)$, and yielded $71 \pm 2 \mathrm{mg} / \mathrm{g}$ extract. 


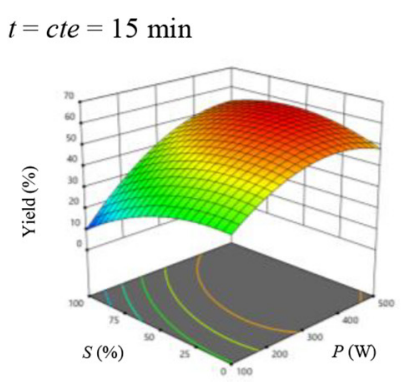

$P=c t e=500 \mathrm{~W}$

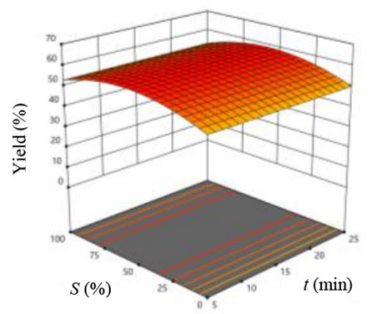

$S=c t e=50 \%$

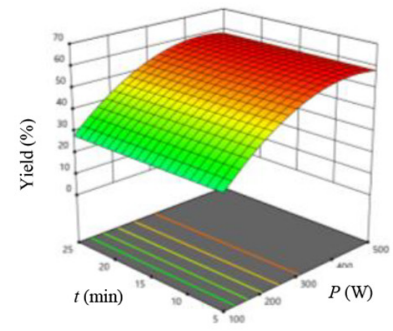

$t=c t e=15 \mathrm{~min}$

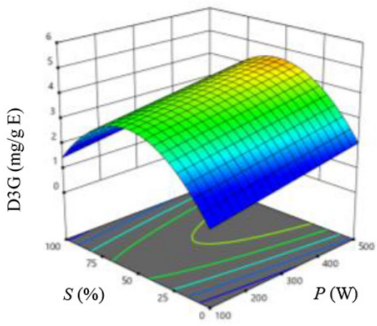

$P=c t e=500 \mathrm{~W}$

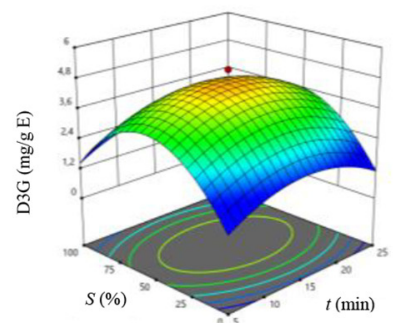

$S=c t e=50 \%$

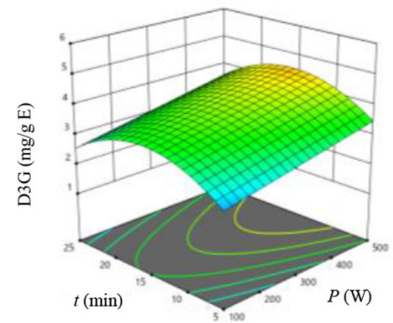

$t=c t e=15 \mathrm{~min}$

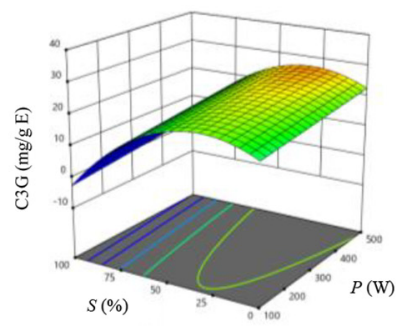

$P=c t e=500 \mathrm{~W}$

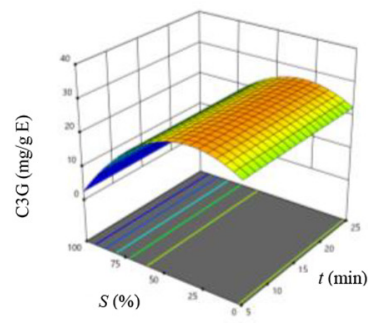

$S=c t e=30 \%$

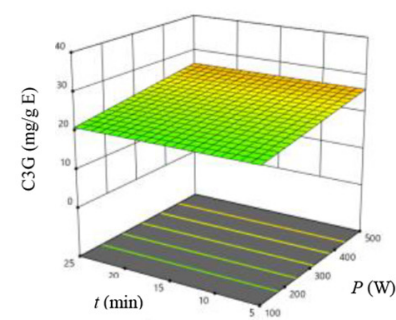

$t=c t e=15 \mathrm{~min}$

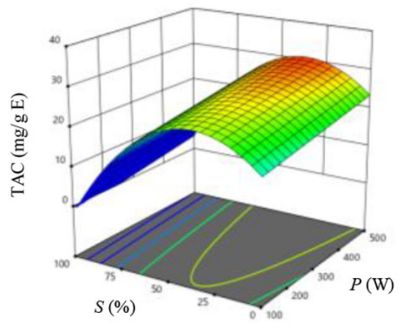

$P=c t e=500 \mathrm{~W}$

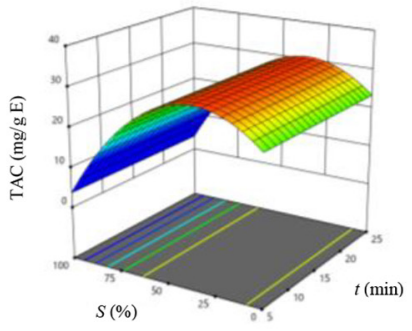

$S=c t e=30 \%$

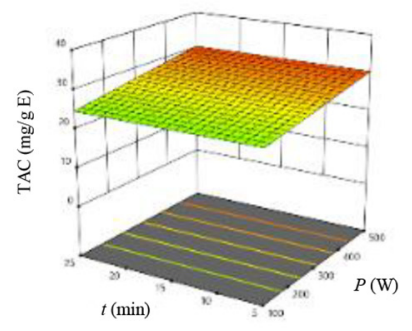

\section{Part B: Statistical distribution}
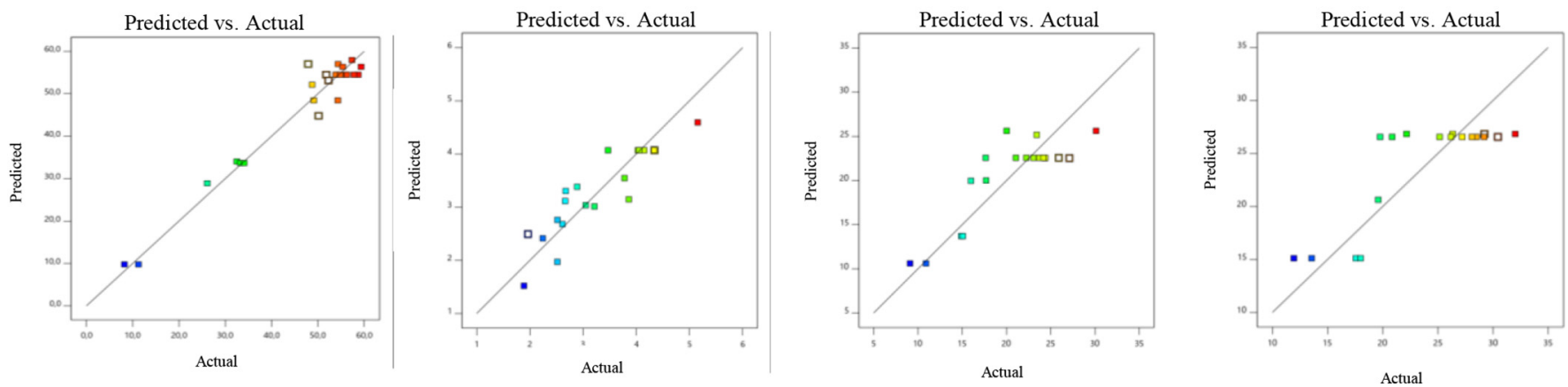

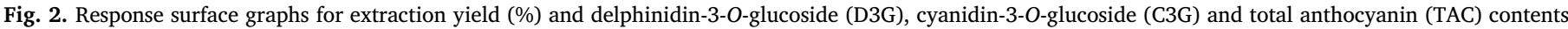

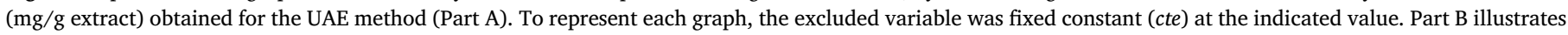
the goodness of fit through the ability to simulate response changes between actual and predicted values.

- For TAC, the conditions were: $t=21.8 \mathrm{~min}, T=47.1{ }^{\circ} \mathrm{C}$, and $S=9.1 \%$ ethanol $(v / v)$, and yielded $81 \pm 2 \mathrm{mg} / \mathrm{g}$ extract.

In general, the optimal HAE conditions were characterized by short extraction times and mean temperatures. Regarding the solvent, although $42.8 \%$ ethanol produced a higher amount of extract, the recovery of anthocyanins from jabuticaba epicarp was favoured by lower solvent percentages (Table S1), indicating that this variable contributes to the selectivity in anthocyanin recovery. This extraction trend can also be observed in the response surface graphs of Fig. 1.

In turn, the conditions that maximized the UAE extraction were as follows:

- For extraction yield, the conditions were: $t=7.49 \mathrm{~min}$,
$P=421.82 \mathrm{~W}$, and $S=48.30 \%$ ethanol $(v / v)$, and originated $59 \pm 1 \%(w / w)$ of extract.

- For D3G, the conditions were: $t=15.37 \mathrm{~min}, P=500 \mathrm{~W}$, and $S=52.52 \%$ ethanol $(v / v)$, and yielded $4.4 \pm 0.2 \mathrm{mg} / \mathrm{g}$ extract.

- For C3G, the conditions were: $t=6.41 \mathrm{~min}, P=500 \mathrm{~W}$, and $S=30.26 \%$ ethanol $(v / v)$, and yielded $27 \pm 2 \mathrm{mg} / \mathrm{g}$ extract.

- For TAC, the conditions were: $t=24.44 \mathrm{~min}, P=500 \mathrm{~W}$, and $S=34.47 \%$ ethanol $(v / v)$, and yielded $31 \pm 2 \mathrm{mg} / \mathrm{g}$ extract.

The UAE process was characterized by short extraction times, high ultrasound power, and medium-low solvent percentages. No selectivity in extraction was verified.

The two extraction methods tested in this study were compared in order to conclude which one is the most suitable to produce an extract 
with a higher amount of anthocyanins from the plant matrix to be recycled within the agri-food chain as a natural colorant. For extraction of intracellular solutes, UAE has shown some advantages over HAE, such as shorter extraction times, lower solvent consumption, and increased mass transfer. These UAE specifications are due to its ability to cause plant tissue/cell walls rapture by ultrasound waves, which facilitates solvent penetration and consequent solute recovery (Albuquerque et al., 2017; López et al., 2019). In fact, ultrasound has been a promising technology for anthocyanin extraction intensification (Backes et al., 2018; Leichtweis et al., 2019; Pinela et al., 2019). However, our results show the opposite, since the anthocyanin content obtained by HAE (81 $\pm 2 \mathrm{mg} / \mathrm{g}$ extract) was more than double obtained by UAE (31 $\pm 2 \mathrm{mg} / \mathrm{g}$ extract) (Table S1). This result may be due, in part, to the stirring system used in each method; in HAE a continuous magnetic stirring system was used, while in UAE the sample was "stirred" only by the power of the ultrasonic probe (therefore, lower powers caused less mixing movement). This result was different from those reported for optimal anthocyanin extraction conditions from other plant matrices, namely extraction of cyanidin-3-rutinoside from Ficus carica L. peels (Backes et al., 2018), delphinidin-3-O-sambubioside and cyanidin-3-Osambubioside from Hibiscus sabdariffa calyces (Pinela et al., 2019), and cyanidin-3-rutinoside and peonidin-3-rutinoside from Prunus spinosa L. fruit epicarp (Leichtweis et al., 2019). However, López et al. (2018) showed that the extraction of cyanidin-3-O-glucoside (the major anthocyanin found in jabuticaba epicarp) from Arbutus unedo L. fruit is also more effective using the HAE technique than UAE. Thus, the nature of anthocyanin, such as its anthocyanidin and sugar molecule, may also be a factor that influences the extraction.

Rodrigues et al. (2015) also accomplished the optimization of cyanidin-3-O-glucoside extraction from jabuticaba epicarp by the UAE technique, but using an open ultrasonic bath $(25 \mathrm{kHz}, 150 \mathrm{~W})$ instead of a probe. The best condition found by the authors were similar to those achieved in this study for the extraction time $(\sim 10 \mathrm{~min})$ and yielded $4.9 \mathrm{mg} \mathrm{C} 3 \mathrm{G} / \mathrm{g}$ dry peel (against $14.85 \mathrm{mg} / \mathrm{g} \mathrm{dw}$ obtained in this study). This difference may be due to the type of ultrasound system used for extractions. In fact, a probe system delivers the ultrasonic intensity on a small surface compared to an ultrasonic bath, thus being more powerful and widely used for bench-scale experiments (Chemat et al., 2017).

\subsubsection{Experimental validation of the optimum extraction conditions}

The optimal conditions that maximize the extraction of total anthocyanins (TAC) from jabuticaba epicarp (Table S1) were experimentally tested to confirm the accuracy of the results and to obtain the anthocyanin-rich extract for incorporation in macarons as a natural colorant. The HAE yielded $76 \pm 1 \mathrm{mg}$ TAC/g E and the UAE yielded $32 \pm 1 \mathrm{mg} \mathrm{TAC} / \mathrm{g} \mathrm{E}$, values that differed in about 6 and $3 \%$ from the predicted values, respectively.

\subsection{Incorporation of anthocyanin-rich extract into macarons}

An anthocyanin-rich extract (AE) of jabuticaba epicarp was produced employing the optimized extraction conditions that lead to the highest anthocyanin content (Table S1). The extract was then incorporated into a bakery product to assess its colouring capacity in a thermal processed foodstuff. For this purpose, the $\mathrm{AE}$ was added as natural colorant in macarons (Fig. S1) and the colour stability of these products was evaluated during a 6-day shelf-life at $\sim 5{ }^{\circ} \mathrm{C}$. In addition, the colour and nutritional value data of macarons formulated with $\mathrm{AE}$ were compared with those of control macarons produced and stored under the same conditions but containing the commercial colorant E163.

\subsubsection{Effects on colour parameters}

The results of the colour parameters $L^{*}$ (lightness), $a^{*}$ (redness) and $b^{*}$ (yellowness) measured on macarons formulated with AE and E163 (control) during a 6-day shelf-life are present in Table 4. As illustrated in Fig. S1, macarons formulated with AE showed a distinct coloration from the control ( $p$-values $<0.05$ ). This difference in colour tone or intensity may be due to a distinct anthocyanin composition and/or content of the two tested colouring agents. It should be noted that the samples with the natural AE presented a more stable coloration during storage, since a decrease in the parameter $b^{*}$ value of the stored control samples was verified (i.e., for the $\mathrm{T} 2$ and $\mathrm{T} 3$ periods). This result highlights the interest in using the developed anthocyanin-rich ingredient as a food additive.

\subsubsection{Effects on nutritional value}

The control of moisture change during the shelf-life of bakery products is very important to preserve their safety and sensory quality (Smith, Daifas, El-Khoury, Koukoutsis, \& El-Khoury, 2004). As shown in Table 4, the macarons formulated with AE had a moisture content similar to the control ( $p$-values $>0.05$ ) and there was no significant absorption or loss of water by the samples during the evaluated shelflive.

Table 4 also shows the nutritional composition for the lyophilised macaron samples. Carbohydrates were the predominant macronutrients $(\sim 71 \mathrm{~g} / 100 \mathrm{~g} \mathrm{dw})$, followed by crude fat $(\sim 17 \mathrm{~g} / 100 \mathrm{~g} \mathrm{dw})$ and protein $(\sim 10 \mathrm{~g} / 100 \mathrm{~g} \mathrm{dw})$. In general, all samples had a similar nutrition composition and no statistical differences were found between macronutrient levels or energy values ( $p$-values $>0.05$ ). The performed HPLC analysis revealed the presence of the monosaccharides fructose and glucose and the disaccharide sucrose, which corresponded to the estimated carbohydrate levels. The sucrose content $(\sim 70 \mathrm{~g} / 100 \mathrm{~g} \mathrm{dw})$ showed no significant differences regardless of the used colouring agent or the evaluated shelf-life. However, the macarons formulated with $\mathrm{AE}$ presented higher fructose and glucose contents than those coloured with the commercial E163 ( $p$-values $<0.05$ ), which can be explained by the amount of reducing sugars that can be found in the jabuticaba epicarp ( 33\%) (Batista et al., 2017). A similar result was described by López et al. (2019) when a anthocyanin-rich Arbutus unedo L. fruit extract was used in the formulation of wafers, which also increased the levels of the same sugars in the obtained samples.

\section{Conclusions}

The extraction of anthocyanins from jabuticaba epicarp by the HAE and UAE methods was tested and optimized using RSM. HAE was more effective and selective than UAE, yielding $81 \pm 2 \mathrm{mg}$ of anthocyanins per $g$ of extract. The solvent concentration was the most relevant variable in both extraction processes, followed by temperature or ultrasound power. After statistical validation of the theoretical models and prediction of the extraction conditions that maximize the anthocyanins recovery, an anthocyanin-rich extract was obtained under the best conditions and incorporated in macarons to validate its colouring capacity. This natural extract gave the macarons a more stable colour than the commercial colorant E163 during a 6-day shelf-life. Overall, this study provides important information for obtaining an anthocyanin-based colorant from jabuticaba epicarp and validates the colouring ability of this natural ingredient in a thermal processed pastry product, which highlights is potential to be used as a natural food colorant.

\section{CRediT authorship contribution statement}

Bianca R. Albuquerque: Conceptualization, Methodology, Investigation, Formal analysis, Writing - original draft. José Pinela: Conceptualization, Methodology, Investigation, Formal analysis, Writing - review \& editing. Lillian Barros: Methodology, Project administration, Writing - review \& editing. M. Beatriz P.P. Oliveira: Conceptualization, Project administration, Writing - review \& editing. Isabel C.F.R. Ferreira: Conceptualization, Methodology, Funding acquisition, Project administration, Writing - review \& editing. 
Table 4

Colour and nutritional value of macarons formulated with anthocyanin-rich extract and colorant E163 (control) during shelf-life.

\begin{tabular}{|c|c|c|c|c|c|c|c|c|c|}
\hline & \multicolumn{3}{|l|}{ T1 (day 0) } & \multicolumn{3}{|c|}{ T2 (3 days of storage) } & \multicolumn{3}{|c|}{ T3 (6 days of storage) } \\
\hline & $\mathrm{AE}$ & Control & $p$-value & $\mathrm{AE}$ & Control & $p$-value & $\mathrm{AE}$ & Control & $p$-value \\
\hline \multicolumn{10}{|l|}{ Colour parameters } \\
\hline$L^{*}$ (lightness) & $80.9 \pm 0.5^{\mathrm{a}}$ & $76.3 \pm 0.3^{\mathrm{b}}$ & $<0.001$ & $80.8 \pm 0.8^{\mathrm{a}}$ & $75.9 \pm 0.7^{\mathrm{b}}$ & $<0.001$ & $79.6 \pm 0.7^{\mathrm{a}}$ & $75.3 \pm 0.5^{\mathrm{b}}$ & $<0.001$ \\
\hline$a^{*}$ (redness) & $6.3 \pm 0.3^{\mathrm{b}}$ & $10.4 \pm 0.3^{\mathrm{a}}$ & $<0.001$ & $6.1 \pm 0.3^{b}$ & $10.7 \pm 0.7^{\mathrm{a}}$ & $<0.001$ & $6.1 \pm 0.4^{\mathrm{b}}$ & $10.6 \pm 0.2^{\mathrm{a}}$ & $<0.001$ \\
\hline$b^{*}$ (yellowness) & $7.6 \pm 0.5^{\mathrm{a}}$ & $1.7 \pm 0.3^{\mathrm{b}}$ & $<0.001$ & $7.6 \pm 0.2^{\mathrm{a}}$ & $0.9 \pm 0.1^{\mathrm{c}}$ & $<0.001$ & $6.8 \pm 0.3^{\mathrm{a}}$ & $0.73 \pm 0.05^{\mathrm{c}}$ & $<0.001$ \\
\hline \multicolumn{10}{|l|}{ Nutritional value } \\
\hline Moisture (g/100 g) & $5.4 \pm 0.8$ & $5.6 \pm 0.3$ & 0.794 & $5.3 \pm 0.1$ & $5.6 \pm 0.2$ & 0.121 & $5.3 \pm 0.4$ & $5.2 \pm 0.2$ & 0.584 \\
\hline Ash $(g / 100 \mathrm{~g} \mathrm{dw})$ & $0.94 \pm 0.01$ & $0.95 \pm 0.01$ & 0.292 & $0.94 \pm 0.04$ & $0.96 \pm 0.01$ & 0.236 & $0.94 \pm 0.01$ & $0.94 \pm 0.03$ & 0.679 \\
\hline Fat $(\mathrm{g} / 100 \mathrm{~g} \mathrm{dw})$ & $17.45 \pm 0.03$ & $17.4 \pm 0.1$ & 0.129 & $17.4 \pm 0.1$ & $17.4 \pm 0.2$ & 0.215 & $17.6 \pm 0.5$ & $17.3 \pm 0.4$ & 0.912 \\
\hline Protein $(\mathrm{g} / 100 \mathrm{~g} \mathrm{dw})$ & $10.55 \pm 0.04$ & $10.51 \pm 0.04$ & 0.115 & $10.1 \pm 0.4$ & $10.4 \pm 0.3$ & 0.595 & $10.3 \pm 0.3$ & $10.4 \pm 0.4$ & 0.665 \\
\hline Carbohydrates ( $\mathrm{g} / 100 \mathrm{~g} \mathrm{dw})$ & $71.1 \pm 0.1$ & $71.1 \pm 0.1$ & 0.597 & $71.2 \pm 0.2$ & $71.4 \pm 0.01$ & 0.182 & $71.1 \pm 0.2$ & $71.3 \pm 0.5$ & 0.581 \\
\hline Energy (kcal/100 g dw) & $483.5 \pm 0.1$ & $483.4 \pm 0.5$ & 0.671 & $483.4 \pm 0.6$ & $483.1 \pm 0.5$ & 0.588 & $484 \pm 2$ & $483 \pm 2$ & 0.415 \\
\hline \multicolumn{10}{|l|}{ Free sugars } \\
\hline Fructose $(\mathrm{g} / 100 \mathrm{~g} \mathrm{dw})$ & $0.576 \pm 0.001$ & $0.17 \pm 0.02$ & $<0.001$ & $0.56 \pm 0.04$ & $0.184 \pm 0.004$ & $<0.001$ & $0.56 \pm 0.03$ & $0.18 \pm 0.02$ & $<0.001$ \\
\hline Glucose (g/100 g dw) & $0.32 \pm 0.02$ & $0.16 \pm 0.05$ & $<0.001$ & $0.33 \pm 0.02$ & $0.13 \pm 0.04$ & $<0.001$ & $0.35 \pm 0.06$ & $0.15 \pm 0.01$ & 0.030 \\
\hline Sucrose $(\mathrm{g} / 100 \mathrm{~g} \mathrm{dw})$ & $70.1 \pm 0.1$ & $70.4 \pm 0.5$ & 0.180 & $70.3 \pm 0.3$ & $70.7 \pm 0.2$ & 0.108 & $70.23 \pm 0.04$ & $70.8 \pm 0.6$ & 0.096 \\
\hline Total sugars $(\mathrm{g} / 100 \mathrm{~g} \mathrm{dw})$ & $71.1 \pm 0.1$ & $70.8 \pm 0.5$ & 0.272 & $71.3 \pm 0.4$ & $71.1 \pm 0.2$ & 0.329 & $71.1 \pm 0.1$ & $71.1 \pm 0.6$ & 0.964 \\
\hline
\end{tabular}

In each line and for each time period, statistical differences ( $p$-value $<0.05)$ between $\mathrm{AE}$ and control samples were assessed by a Student's $t$-test, while the effect of storage time was assessed by a one-way ANOVA (different letters indicate significant statistical differences; there are no differences when no letters are displayed). AE: macarons with anthocyanin-rich extract; Control: macarons with the commercial colorant E163; dw: dry weight.

\section{Declaration of Competing Interest}

The authors declare that they have no known competing financial interests or personal relationships that could have appeared to influence the work reported in this paper.

\section{Acknowledgments}

The authors are grateful to the Foundation for Science and Technology (FCT, Portugal) and European Regional Development Fund (ERDF; Fundo Europeu de Desenvolvimento Regional - FEDER) under Programme PT2020 for financial support to CIMO (UID/AGR/00690/ 2019). B. Albuquerque thanks FCT for the PhD grant (SFRH/BD/ 136370/2018). J. Pinela and L. Barros thank their research contracts (national funding by FCT, P.I., through the institutional scientific employment program-contract). This work was funded by FEDER through the Regional Operational Program North 2020, within the scope of project Mobilizador Norte-01-0247-FEDER-024479: ValorNatural. The authors are also grateful to FEDER-Interreg España-Portugal programme for financial support through the project 0377_Iberphenol_6_E and and TRANSCoLAB 0612_TRANS_CO_LAB_2_P. The authors also thank Susana Aleixo from Doce Opções for the macarons production.

\section{Appendix A. Supplementary data}

Supplementary data to this article can be found online at https:// doi.org/10.1016/j.foodchem.2020.126364.

\section{References}

Albuquerque, B. R., Pereira, C., Calhelha, R. C., José Alves, M., Abreu, R. M. V., Barros, L., .. Ferreira, I. C. F. R. (2020). Jabuticaba residues (Myrciaria jaboticaba (Vell.) Berg) are rich sources of valuable compounds with bioactive properties. Food Chemistry, 309, 125735.

Albuquerque, B. R., Prieto, M. A., Barreiro, M. F., Rodrigues, A., Curran, T. P., Barros, L., \& Ferreira, I. C. F. R. (2017). Catechin-based extract optimization obtained from Arbutus unedo L. fruits using maceration/microwave/ultrasound extraction techniques. Industrial Crops and Products, 95, 404-415.

Albuquerque, B. R., Prieto, M. A., Vazquez, J. A., Barreiro, M. F., Barros, L., \& Ferreira, I. C. F. R. (2018). Recovery of bioactive compounds from Arbutus unedo L. fruits: Comparative optimization study of maceration/microwave/ultrasound extraction techniques. Food Research International, 109, 455-471.

AOAC International. (2016). Association of Official Analytical Chemists (20th ed.). Rockville.

Backes, E., Pereira, C., Barros, L., Prieto, M. A., Genena, A., Barreiro, M. F., \& Ferreira, I.
C. F. R. (2018). Recovery of bioactive anthocyanin pigments from Ficus carica L. peel by heat, microwave, and ultrasound based extraction techniques. Food Research International, 113, 197-209.

Barros, L., Pereira, E., Calhelha, R. C., Dueñas, M., Carvalho, A. M., Santos-Buelga, C., \& Ferreira, I. C. F. R. (2013). Bioactivity and chemical characterization in hydrophilic and lipophilic compounds of Chenopodium ambrosioides L. Journal of Functional Foods, 5(4), 1732-1740.

Basu, A., \& Kumar, G. S. (2015a). Binding of carmoisine, a food colorant, with hemoglobin: Spectroscopic and calorimetric studies. Food Research International, 72, 54-61.

Basu, A., \& Kumar, G. S. (2015b). Interaction of toxic azo dyes with heme protein: Biophysical insights into the binding aspect of the food additive amaranth with human hemoglobin. Journal of Hazardous Materials, 289, 204-209.

Batista, Â. G., Soares, E. S., Mendonça, M. C. P., da Silva, J. K., Dionísio, A. P., Sartori, C. R., ... Maróstica Júnior, M. R. (2017). Jaboticaba berry peel intake prevents insulinresistance-induced tau phosphorylation in mice. Molecular Nutrition \& Food Research, 61(10), 1600952.

Boulekbache-Makhlouf, L., Medouni, L., Medouni-Adrar, S., Arkoub, L., \& Madani, K. (2013). Effect of solvents extraction on phenolic content and antioxidant activity of the byproduct of eggplant. Industrial Crops and Products, 49, 668-674.

Cai, Z., Qu, Z., Lan, Y., Zhao, S., Ma, X., Wan, Q., ... Li, P. (2016). Conventional, ultrasound-assisted, and accelerated-solvent extractions of anthocyanins from purple sweet potatoes. Food Chemistry, 197, 266-272.

Chemat, F., Rombaut, N., Meullemiestre, A., Turk, M., Perino, S., Fabiano-Tixier, A.-S., \& Abert-Vian, M. (2017). Review of green food processing techniques. preservation, transformation, and extraction. Innovative Food Science \& Emerging Technologies, 41, 357-377.

Ćujić, N., Šavikin, K., Janković, T., Pljevljakušić, D., Zdunić, G., \& Ibrić, S. (2016). Optimization of polyphenols extraction from dried chokeberry using maceration as traditional technique. Food Chemistry, 194, 135-142.

EFSA (2013). Scientific Opinion on the re-evaluation of anthocyanins (E 163) as a food additive. EFSA Journal, 11(4), 3145

Espada-Bellido, E., Ferreiro-González, M., Carrera, C., Palma, M., Barroso, C. G., \& Barbero, G. F. (2017). Optimization of the ultrasound-assisted extraction of anthocyanins and total phenolic compounds in mulberry (Morus nigra) pulp. Food Chemistry, 219, 23-32.

Gonçalves, G. A., Soares, A. A., Correa, R. C. G., Barros, L., Haminiuk, C. W. I., Peralta, R. M., ... Bracht, A. (2017). Merlot grape pomace hydroalcoholic extract improves the oxidative and inflammatory states of rats with adjuvant-induced arthritis. Journal of Functional Foods, 33, 408-418.

He, B., Zhang, L. L., Yue, X. Y., Liang, J., Jiang, J., Gao, X. L., \& Yue, P. X. (2016). Optimization of ultrasound-assisted extraction of phenolic compounds and anthocyanins from blueberry (Vaccinium ashei) wine pomace. Food Chemistry, 204, 70-76.

Iberahim, N., Sethupathi, S., Goh, C. L., Bashir, M. J. K., \& Ahmad, W. (2019). Optimization of activated palm oil sludge biochar preparation for sulphur dioxide adsorption. Journal of Environmental Management, 248, 109302.

Khazaei, K. M., Jafari, S. M., Ghorbani, M., \& Kakhki, A. H. (2016). Optimization of anthocyanin extraction from saffron petals with response surface methodology. Food Analytical Methods, 9, 1993-2001.

Leichtweis, M. G., Pereira, C., Prieto, M. A., Barreiro, M. F., Beraldi, I. J., Barros, L., \& Ferreira, I. C. F. R. (2019). Ultrasound as a rapid and low-cost extraction procedure to obtain anthocyanin-based colorants from Prunus spinosa L. fruit epicarp: Comparative study with conventional heat-based extraction. Molecules, 24(573), 1-17.

Leong, H. Y., Show, P. L., Lim, M. H., Ooi, C. W., \& Ling, T. C. (2018). Natural red 
pigments from plants and their health benefits: A review. Food Reviews International, 34(5), 463-482.

Li, D., Wang, P., Luo, Y., Zhao, M., \& Chen, F. (2017). Health benefits of anthocyanins and molecular mechanisms: Update from recent decade. Critical Reviews in Food Science and Nutrition, 57(8), 1729-1741.

López, C. J., Caleja, C., Prieto, M. A., Barreiro, M. F., Barros, L., \& Ferreira, I. C. F. R. (2018). Optimization and comparison of heat and ultrasound assisted extraction techniques to obtain anthocyanin compounds from Arbutus unedo L. fruits. Food Chemistry, 264, 81-91.

López, C. J., Caleja, C., Prieto, M. A., Sokovic, M., Calhelha, R. C., Barros, L., \& Ferreira, I. C. F. R. (2019). Stability of a cyanidin-3-O-glucoside extract obtained from Arbutus unedo L. and incorporation into wafers for colouring purposes. Food Chemistry, 275, 426-438.

Maran, J. P., Priya, B., \& Manikandan, S. (2014). Modeling and optimization of supercritical fluid extraction of anthocyanin and phenolic compounds from Syzygium cumini fruit pulp. Journal of Food Science and Technology, 51(9), 1938-1946.

Martins, N., \& Ferreira, I. C. F. R. (2017). Wastes and by-products: Upcoming sources of carotenoids for biotechnological purposes and health-related applications. Trends in Food Science \& Technology, 62, 33-48.

Martins, N., Roriz, C. L., Morales, P., Barros, L., \& Ferreira, I. C. F. R. (2016). Food colorants: Challenges, opportunities and current desires of agro-industries to ensure consumer expectations and regulatory practices. Trends in Food Science \& Technology, $52,1-15$.

Masone, D., \& Chanforan, C. (2015). Study on the interaction of artificial and natural food colorants with human serum albumin: A computational point of view. Computational Biology and Chemistry, 56, 152-158.

Ngamwonglumlert, L., Devahastin, S., \& Chiewchan, N. (2017). Natural colorants: Pigment stability and extraction yield enhancement via utilization of appropriate pretreatment and extraction methods. Critical Reviews in Food Science and Nutrition, 57(15), 3243-3259.

Ordóñez-Santos, L. E., Pinzón-Zarate, L. X., \& González-Salcedo, L. O. (2015).

Optimization of ultrasonic-assisted extraction of total carotenoids from peach palm fruit (Bactris gasipaes) by-products with sunflower oil using response surface methodology. Ultrasonics Sonochemistry, 27, 560-566.

Paludo, M., Colombo, R., Teixeira, J., Hermosín-Gutiérrez, I., Ballus, C., \& Godoy, H. (2019). Optimizing the extraction of anthocyanins from the skin and phenolic compounds from the seed of jabuticaba fruits (Myrciaria jabuticaba (Vell.) O. Berg) with ternary mixture experimental designs. Journal of the Brazilian Chemical Society, 30(7), $1506-1514$.

Pinela, J., Prieto, M. A., Barros, L., Carvalho, A. M., Oliveira, M. B. P. P., Saraiva, J. A., \& Ferreira, I. C. F. R. (2018). Cold extraction of phenolic compounds from watercress by high hydrostatic pressure: Process modelling and optimization. Separation and Purification Technology, 192, 501-512.

Pinela, J., Prieto, M. A., Pereira, E., Jabeur, I., Barreiro, M. F., Barros, L., \& Ferreira, I. C. F. R. (2019). Optimization of heat- and ultrasound-assisted extraction of anthocyanins from Hibiscus sabdariffa calyces for natural food colorants. Food Chemistry, 275, 309-321.

Regulation (EU) No 1169/2011 of the European Parliament and of the Council. (2011).

Rodrigues, S., Fernandes, F. A. N., de Brito, E. S., Sousa, A. D., \& Narain, N. (2015). Ultrasound extraction of phenolics and anthocyanins from jabuticaba peel. Industrial Crops and Products, 69, 400-407.

Santos, D. T., \& Meireles, M. A. A. (2011). Optimization of bioactive compounds extraction from jabuticaba (Myrciaria cauliflora) skins assisted by high pressure CO2. Innovative Food Science \& Emerging Technologies, 12(3), 398-406.

Santos, D. T., Veggi, P. C., \& Meireles, M. A. A. (2012). Optimization and economic evaluation of pressurized liquid extraction of phenolic compounds from jabuticaba skins. Journal of Food Engineering, 108(3), 444-452.

Smith, J. P., Daifas, D. P., El-Khoury, W., Koukoutsis, J., \& El-Khoury, A. (2004). Shelf life and safety concerns of bakery products - a review. Critical Reviews in Food Science and Nutrition, 44(1), 19-55.

You, Y., Han, X., Guo, J., Guo, Y., Yin, M., Liu, G., ... Zhan, J. (2018). Cyanidin-3-glucoside attenuates high-fat and high-fructose diet-induced obesity by promoting the thermogenic capacity of brown adipose tissue. Journal of Functional Foods, 41, 62-71.

Zou, T., Wang, D., Guo, H., Zhu, Y., Luo, X., Liu, F., \& Ling, W. (2012). Optimization of microwave-assisted extraction of anthocyanins from mulberry and identification of anthocyanins in extract using HPLC-ESI-MS. Journal of Food Science, 77(1), 46-50. 